\title{
Polymerization behavior within adhesive layer of one- and two-step self-etch adhesives: A micro-Raman spectroscopic study
}

\author{
Wakae SAKANO ${ }^{1}$, Masatoshi NAKAJIMA ${ }^{1}$, Taweesak PRASANSUTTIPORN², Richard M. FOXTON ${ }^{3}$ \\ and Junji TAGAMI ${ }^{1,4}$ \\ ${ }^{1}$ Cariology and Operative Dentistry, Department of Restorative Sciences, Tokyo Medical and Dental University, 1-5-45, Yushima, Bunkyo-ku, Tokyo \\ 113-8549, Japan \\ ${ }^{2}$ Division of Operative Dentistry, Department of Restorative Dentistry and Periodontology, Faculty of Dentistry, ChiangMai University, ChiangMai \\ 50200, Thailand \\ ${ }^{3}$ Division of Conservative Dentistry, King's College London Dental Institute at Guy's, King's and St Thomas' Hospitals, King's College London, Floor \\ 25, London Bridge, London, SE1-9RT, UK \\ ${ }^{4}$ Global Center Excellence (GCOE) Program; International Research Center for Molecular Science in Tooth and Bone Diseases, Tokyo Medical and \\ Dental University, 1-5-45, Yushima, Bunkyo-ku, Tokyo 113-8549, Japan \\ Corresponding author, Masatoshi NAKAJIMA; E-mail: nakajima.ope@tmd.ac.jp
}

\begin{abstract}
This study investigated the polymerization behavior within the adhesive layer of one- and two-step self-etch adhesives at the dentincomposite interface. Dentin surfaces were applied with Clearfil $\mathrm{S}^{3}$ Bond (TS), Clearfil $\mathrm{S}^{3}$ Bond Plus (TSP) and Clearfil SE Bond (SE), and then placed with a light-curing resin composite. After water storage for $24 \mathrm{~h}$, the bonded teeth were sectioned and polished perpendicular to the adhesive interface, and the degree of conversion (DC) of the adhesive layer between the dentin and composite were determined using micro-Raman analysis. For all the adhesives, the DCs of the adhesive layers significantly decreased near the adhesive-composite join $(p<0.05)$. For the maximum DC value $\left(\mathrm{P}_{\max }\right)$ and the $\mathrm{DC}$ value at the adhesive-composite join $\left(\mathrm{P}_{\text {itt }}\right)$, TS was significantly lower than TSP and SE $(p<0.05)$. The polymerization of oxygen-inhibited layer at the top of the adhesive could not reach maximum DC even after polymerization of the overlying resin composite.
\end{abstract}

Keywords: Self-etch adhesives, Degree of conversion, Oxygen-inhibited layer, Micro-Raman spectroscopy, Polymerization behavior

\section{INTRODUCTION}

The polymerization ability of the adhesive layer is one of the factors affecting the integrity of adhesion between the tooth substrate and resin composite. In the case of light-curing adhesive, an uncured resin layer (oxygeninhibited layer) at the uppermost surface is formed when photo-polymerization occurs in air ${ }^{1}$. This uncured resin layer can polymerize while curing the overlying resin composite ${ }^{2)}$.

Recently developed one-step self-etch adhesives contain acidic functional monomer, hydrophilic monomers, hydrophobic monomers, water and organic solvents in one bottle, and have higher hydrophilicity even after polymerization ${ }^{3,4)}$. Ideally, their water/ solvents should be completely removed from the adhesive layer prior to the polymerization of the adhesive, because the residual water/solvents decrease the degree of conversion of resin monomers ${ }^{5,6)}$ and generate porosities in the adhesive interface that could permit water diffusion ${ }^{6,7)}$. The residual contents of solvents in the adhesive layer become a critically important factor in compromising the integrity and/or the longevity of adhesive interface ${ }^{8,99}$. Therefore, solvent evaporation by air-blowing is a very important step in the bonding procedure of one-step self-etch adhesives ${ }^{10)}$, resulting in a thin adhesive layer. However, complete removal of the solvents is difficult to achieve by airblowing in the clinical situation ${ }^{11}$. Additionally, when the thin layer of adhesive is light-cured, it may not really polymerize due to oxygen inhibition ${ }^{11}$. The final degree of conversion of the adhesive would only be reached after polymerization of the first layer of overlying resin composite ${ }^{11}$.

On the other hand, for two-step self-etch adhesive systems, which separately provide an etching-primingstep and bonding-step, the adhesive agent is relatively hydrophobic ${ }^{12}$, not including water and organic solvents. Therefore, air-blowing to remove the solvents is not required in the bonding procedures before lightcuring the adhesive layer, and the relatively higher viscosity of the adhesive provides a thick adhesive layer in the interface of the two-step self-etch adhesive compared with a one-step self-etch adhesive. Increased viscosity of resin composite can decrease the depth of oxygen diffusion and increase the degree of conversion at the uppermost subsurface ${ }^{13)}$. Presumably, a two-step self-etch adhesive might have a different behavior of degree of conversion from a one-step self-etch adhesive after polymerization of the overlying resin composite.

Micro-Raman spectroscopy is a useful analytical technique for accurately determining the degree of conversion of a resin sample and recording the profile of conversion vs depth ${ }^{13)}$. Recent studies with micro-Raman spectroscopy have investigated the polymerization behaviors of one-step self-etch adhesives on dentin, excluding the oxygen inhibition effect $^{14,15}$. However, there have been few studies on 
the polymerization behavior within the adhesive layer with oxygen inhibition effect under the resin composite restoration. The chemical and mechanical properties of the adhesive layer with oxygen inhibition effect would be dependent upon indirect light-irradiated intensity to adhesive layer through resin composite restoration as well as direct light-irradiated intensity, which affect the bonding performance of a resin composite restoration ${ }^{16)}$.

The purpose of this study was to investigate polymerization behavior (conversion $v s$ depth) within the adhesive layer in resin composite restorations using one- and two-step self-etch adhesives, by measuring the degree of conversion (DC) using micro-Raman spectroscopy. The null hypothesis tested was that there were no differences in DC of the adhesive layer between one- and two-step self-etch adhesives and no change of DC between different depths in each adhesive.

\section{MATERIALS AND METHODS}

Specimen preparation

Thirty extracted human non-carious third molars stored frozen were used in this study, according to a protocol approved by Human Research Ethics Committee, Tokyo Medical and Dental University, Tokyo, Japan (No.725). The occlusal enamel was removed perpendicular to the long axis of the tooth to expose flat surface of sound dentin under water lubrication. Smear layers were produced by grinding using 600 -grit silicon carbide $(\mathrm{SiC})$ paper under running water. The teeth were randomly divided into three groups of ten teeth each.

The dentin surfaces were demarcated using a black plastic ring, $2 \mathrm{~mm}$ in height and $8 \mathrm{~mm}$ in bore diameter and then applied with one-step self-etch adhesives (Clearfil $\mathrm{S}^{3}$ Bond (TS), Clearfil $\mathrm{S}^{3}$ Bond Plus (TSP); Kuraray Noritake Dental Inc., Tokyo, Japan) or a twostep self-etch adhesive (Clearfil SE Bond (SE); Kuraray Noritake Dental Inc., Tokyo, Japan) according to the manufacturers' instructions (Table 1). The adhesive materials used in the study are listed in Table 1. After light-curing of the adhesive with a light-curing unit (Optilux 501, Kerr Corp., Orange, GA, USA) with an intensity of $850 \mathrm{~mW} / \mathrm{cm}^{2}$, resin composites (Clearfil Majesty, transparent shade, Kuraray Noritake Dental Inc., Tokyo, Japan) were packed into the plastic ring by means of a bulk filling technique. The top of the ring was flattened using a plastic matrix strip and then light-cured for $20 \mathrm{~s}$ with the same light intensities as for the bonding procedures. After storage in water at $37^{\circ} \mathrm{C}$ for $24 \mathrm{~h}$, the bonded teeth were sectioned perpendicular to the adhesive interface using the watercooling low speed diamond saw (Isomet saw; Buehler, LAKE Bluff, IL, USA) to obtain beam-shaped specimens with the dimension $2.0 \mathrm{~mm}$ width and $2.0 \mathrm{~mm}$ depth. After being embedded in epoxy resin, the specimens were ground flat using SiC paper up to 4,000-grit and then polished with diamond paste down to $1 / 4 \mu \mathrm{m}$.

Table 1 Materials used and bonding procedures of experimental groups $(n=10)$

\begin{tabular}{|c|c|c|c|}
\hline Materials & Manufacturer & Batch No. & Compositions \\
\hline $\begin{array}{l}\text { Clearfil S }{ }^{3} \text { Bond } \\
\text { (TS) }\end{array}$ & $\begin{array}{l}\text { Kuraray Noritake } \\
\text { Dental Inc., } \\
\text { Tokyo, Japan }\end{array}$ & 011112 & $\begin{array}{c}\text { HEMA, bisphenol-A-diglycidylmethacrylate, 10-MDP, } \\
\text { Silanated colloidal silica, CQ, Ethanol, Initiators, } \\
\text { Accelerators, Water }\end{array}$ \\
\hline $\begin{array}{l}\text { Clearfil S }{ }^{3} \text { Bond Plus } \\
\text { (TSP) }\end{array}$ & $\begin{array}{l}\text { Kuraray Noritake } \\
\text { Dental Inc., } \\
\text { Tokyo, Japan }\end{array}$ & 011117 & $\begin{array}{c}\text { HEMA, bisphenol-A-diglycidylmethacrylate, Ethanol, } \\
\text { Sodium Fluoride, 10-MDP, Hydrophilic aliphatic dimethacrylate, } \\
\text { Hydrophobic aliphatic methacrylate, colloidal silica, } \\
\text { CQ, New photo-initiators, Water }\end{array}$ \\
\hline $\begin{array}{l}\text { Clearfil SE Bond } \\
\text { (SE) }\end{array}$ & $\begin{array}{l}\text { Kuraray Noritake } \\
\text { Dental Inc., } \\
\text { Tokyo, Japan }\end{array}$ & 011595 & $\begin{array}{l}\text { Primer: 10-MDP, HEMA, Dimethacrylate hydrophilic, } \\
\text { CQ, N,N-Diethanol-p-toluidine, Water. } \\
\text { Adhesive: 10-MDP, bisphenol-A-diglycidylmethacrylate, HEMA, } \\
\text { Hydrophobic aliphatic methacrylate, CQ, Initiators, Accelerators }\end{array}$ \\
\hline $\begin{array}{l}\text { Clearfil Majesty } \\
\text { (Transparent shade) }\end{array}$ & $\begin{array}{l}\text { Kuraray Noritake } \\
\text { Dental Inc., } \\
\text { Tokyo, Japan }\end{array}$ & 0011DA & $\begin{array}{c}\text { bisphenol-A-diglycidylmethacrylate, Silanated barium glass filler, } \\
\text { Hydrophobic aromatic dimethacrylate, Hydrophobic aliphatic } \\
\text { methacrylate, CQ, Initiators, Accelerators, Pigments }\end{array}$ \\
\hline
\end{tabular}

10-MDP: 10-methacryloyloxydecyl dihydrogen phosphate; HEMA: 2-hydroxyethyl methacrylate;

CQ: dl-Camphorquinone

*Details of bonding procedures.

Dental adhesives

Clearfil $\mathrm{S}^{3}$ Bond: 1 . Apply adhesive $20 \mathrm{~s}$, dry with high-pressure air flow. 2. Light cure $10 \mathrm{~s}$.

Clearfil $\mathrm{S}^{3}$ Bond Plus: 1. Apply adhesive $10 \mathrm{~s}$, dry with low to high-pressure air flow. 2. Light cure $10 \mathrm{~s}$.

Clearfil SE Bond: 1. Apply primer $20 \mathrm{~s}$, dry with low to high-pressure air flow. 2. Apply adhesive, air-thinning with lowpressure air flow. 3. Light cure $10 \mathrm{~s}$. 


\section{Micro-Raman spectroscopy}

A LabRAM ARAMIS Raman spectroscopy (HORIBA Ltd., Tokyo, Japan) using monochromatic radiation emitted by a semiconductor laser (a wavelength of 785 $\mathrm{nm}$ and excitation power of $105 \mathrm{~mW}$ ) was employed. It was equipped with a confocal microscope, a piezoelectric $\mathrm{XY}$ stage with a minimum step width of $1 \mu \mathrm{m}$, and the focus of the laser beam in conjunction with the CCD camera provided a spatial resolution of $1 \mu \mathrm{m}$. The spectra were Raman-shift-frequency calibrated with known lines of silicon (Fig. 1-a). The laser was focused through a $100 \times$ objective to obtain a beam diameter of $1 \mu \mathrm{m}$. The spectral region of this study was from 200$2,000 \mathrm{~cm}^{-1}$, with an average spectral resolution was at $9.0 \mathrm{~cm}^{-1}$. Raman spectra were acquired starting from the dentin towards the composite resin at $1 \mu \mathrm{m}$ intervals (Fig. 2-a and 2-b). Samples were kept moist throughout the experimental procedure. Postprocessing was performed in the Lab Spec 5 (HORIBA Ltd., Tokyo, Japan) and included in the analysis with modeling which allowed distinguishing spectral components of the dentin, adhesive and resin composite.

\section{Measurement of $D C$}

For calculation of the DC, the absorbance peak intensities of vinyl $\mathrm{C}=\mathrm{C}$ located at $1,640 \mathrm{~cm}^{-1}$ and phenyl $\mathrm{C}=\mathrm{C}$ located at $1,608 \mathrm{~cm}^{-1}$ were observed to compare spectra before and after the polymerization reaction (Fig. 1-b and 1-c), and the double bond conversion was determined using the following equation:

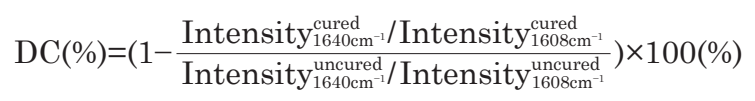

The DC was obtained by subtracting the percentage of the remaining carbon-carbon double bond from $100 \%$.

After calculating the percentage of double bond conversion values, the conversion depth profile in each
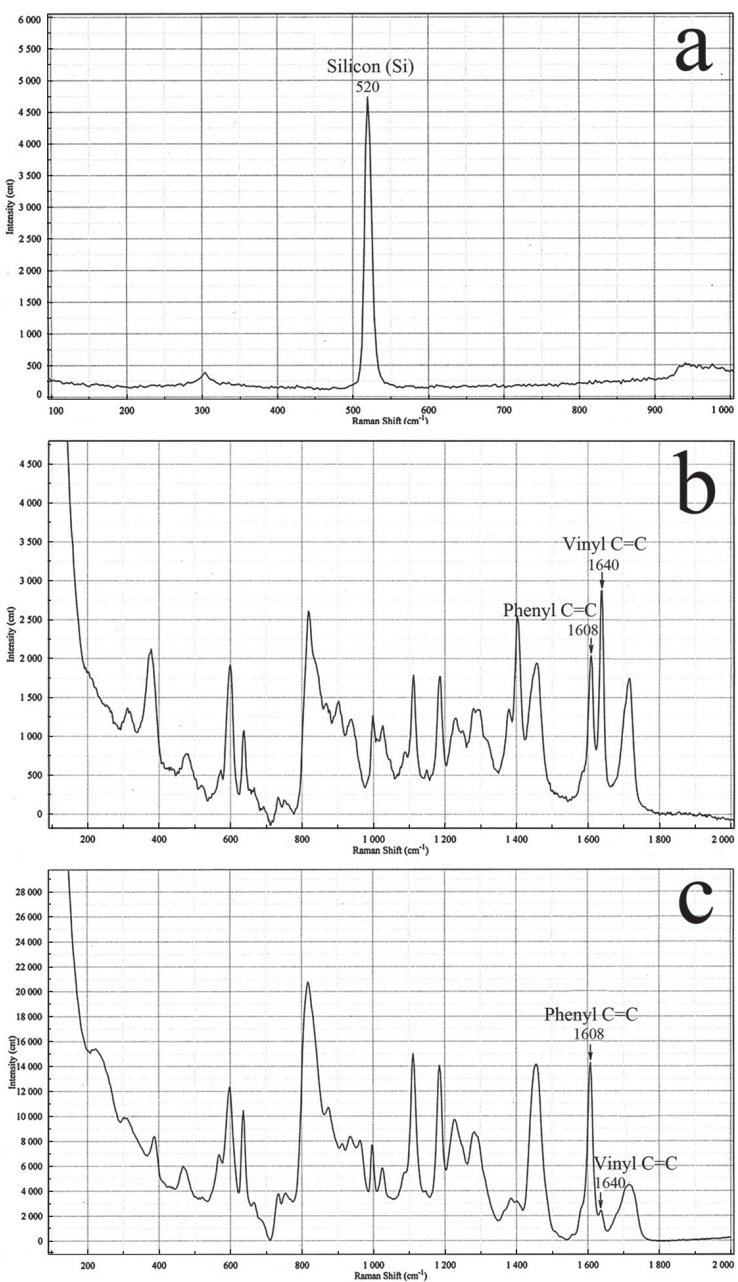

Fig. 1 (a); Representative micro-Raman spectra of silicon for calibration. (b); Representative micro-Raman spectra of $\mathrm{C}=\mathrm{C}$ in uncured adhesive resin (Clearfil SE Bond). (c); Representative micro-Raman spectra of $\mathrm{C}=\mathrm{C}$ in cured adhesive resin (Clearfil SE Bond).

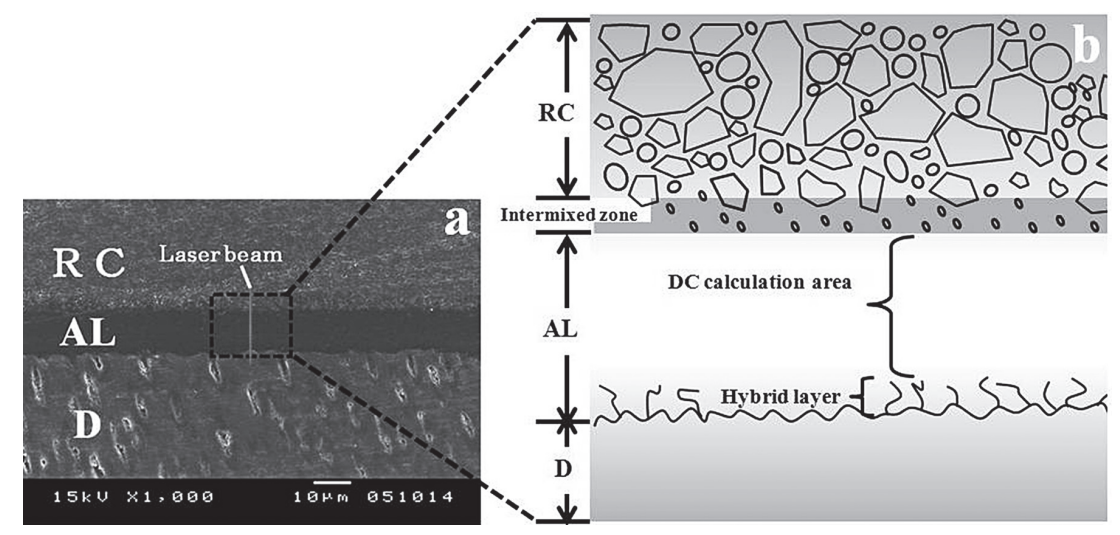

Fig. 2 Micro-Raman spectra were obtained with the laser beam at a spatial resolution of $1 \mu \mathrm{m}$. The mapping spectra acquired at $1 \mu \mathrm{m}$ intervals across the adhesive-resin interface. RC; resin composite, AL; adhesive layer, $\mathrm{D}$; dentin. 
specimen was plotted as shown in Figs. 3 and 4. From the conversion profile of each specimen, the maximum DC value $\left(\mathrm{P}_{\max }\right)$ and $\mathrm{DC}$ value at the adhesive-composite join $\left(\mathrm{P}_{\text {itf }}\right)$ were determined (Fig. 3) and the reduction ratio of $\mathrm{P}_{\text {itf }}$ to $\mathrm{P}_{\max }$ was calculated. In order to evaluate the reduction area of $\mathrm{DC}$, the thickness from the adhesive-composite join to point of $\mathrm{P}_{95}$ (defined as $95 \%$ $\mathrm{DC}$ value of $\left.\mathrm{P}_{\max }\right)$ was calculated $\left(\mathrm{D}_{95}\right)$. All the samples decreased the degree of conversion (DC) to the adhesivecomposite join, but their displacements were not smooth. However, after $95 \%$ reduction of $\mathrm{P}_{\max }$ all the samples

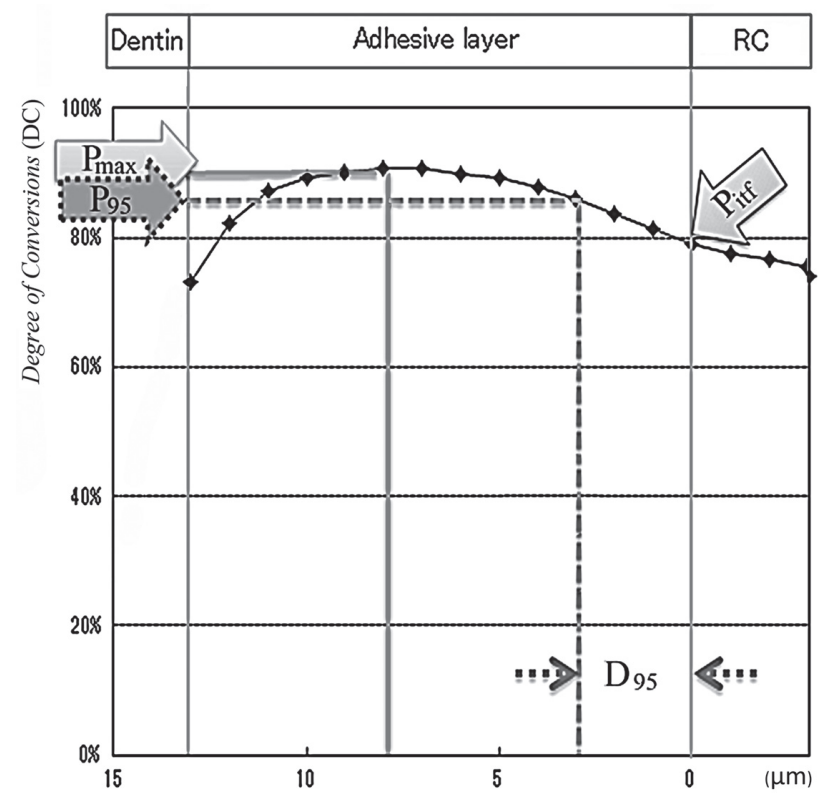

Fig. 3 Illustration for describe the DC of adhesive that was measured by formula (\%DC).

$\mathrm{RC}$; resin composite, $\mathrm{P}_{\max }$; the percentage of maximum DC, $\mathrm{P}_{\text {itf }}$; the percentage of $\mathrm{DC}$ at adhesive-resin interface, $\mathrm{P}_{95} ; 95 \%$ of $\mathrm{P}_{\max }$ value, $\mathrm{D}_{95}$; the distance from adhesive-resin interface to $\mathrm{P}_{95}$ in Y-axis. did not re-increase. Therefore, $\mathrm{P}_{95}$ point was defined as reduction border of $\mathrm{DC}$.

\section{Statistical analysis}

Data on the DCs $\left(\mathrm{P}_{\max }\right.$ and $\left.\mathrm{P}_{\mathrm{itf}}\right)$, reduction ratio of $\mathrm{DC}$ and reduction thickness $\left(\mathrm{D}_{95}\right)$ were analyzed using oneway ANOVA, together with the $t$-test at the confidence level of $95 \%$.

\section{RESULTS}

Representative Raman spectra of SE are presented in Fig. 1. The two Raman bands 1,640 and 1,608 $\mathrm{cm}^{-1}$ (indicated by the arrows in Fig. 1-b and 1-c) were employed to determine the $\mathrm{DC}$ of the adhesive. It can be discerned from the figure that band intensities of 1,640 $\mathrm{cm}^{-1}$ relative to $1,608 \mathrm{~cm}^{-1}$ for uncured adhesives (Fig. 1-b) showed apparently higher levels when compared with cured adhesives (Fig. 1-c).

The representative conversion profiles of the tested adhesives were exhibited in Fig 4. The profiles were different between TS, TSP and SE, while all of the adhesives denoted a decrease of DC in profile, near the adhesive-composite join.

The results of maximum $\mathrm{DC}\left(\mathrm{P}_{\max }\right)$, $\mathrm{DC}$ at the adhesive-composite join $\left(\mathrm{P}_{\text {itf }}\right)$ and reduction ratio of $\mathrm{P}_{\text {itf }}$ to $\mathrm{P}_{\max }$ of each adhesive are shown in Table 2. For all adhesives, $\mathrm{P}_{\text {itf }}$ were significantly lower than $\mathrm{P}_{\max }$ $(p<0.05)$. TS had significantly lower $\mathrm{P}_{\max }$ and $\mathrm{P}_{\text {itf }}$ than TSP and SE $(p<0.05)$, but there were no significant differences in $\mathrm{P}_{\max }$ and $\mathrm{P}_{\text {itf }}$ between TSP and SE ( $\left.p>0.05\right)$. Furthermore, TS had a higher reduction ratio of $31.1 \%$ than TSP $(11.7 \%)$ and SE $(10.9 \%)(p<0.05)$. The results of the thickness from adhesive-composite join to point of $95 \%$ DC of $\mathrm{P}_{\max }\left(\mathrm{D}_{95}\right)$ are also shown in Table 2. TSP had significantly lower $\mathrm{D}_{95}$ than that of SE and TS $(p<0.05)$.

\section{DISCUSSION}

In order to establish a superior adhesive resin composite restoration, the adhesive layer has to achieve crucial joins to the overlying resin composite material as well
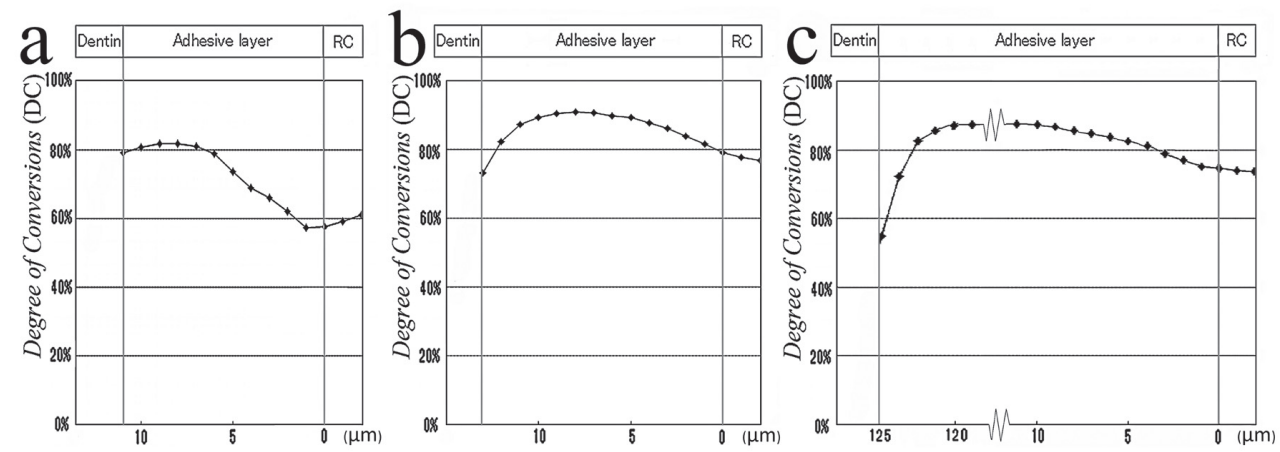

Fig. 4 Illustration for describe the mean DC of adhesives. (a); Clearfil Tri-S ${ }^{3}$ Bond (TS), (b); Clearfil Tri-S ${ }^{3}$ Bond Plus (TSP), (c); Clearfil SE Bond (SE). 
Table 2 The results of micro-Raman analysis

\begin{tabular}{lccc}
\hline \multicolumn{1}{c}{ Adhesives } & Clearfil S ${ }^{3}$ Bond (TS) & Clearfil S Bond Plus (TSP) $^{3}$ Clearfil SE Bond (SE) \\
\hline Maximum DC (\%) $\left(\mathrm{P}_{\max }\right)$ & $82.2(1.2)^{\mathrm{A}, \mathrm{a}}$ & $88.6(3.5)^{\mathrm{B}, \mathrm{a}}$ & $88.1(0.5)^{\mathrm{B}, \mathrm{a}}$ \\
DC at adhesives-composite join (\%) $\left(\mathrm{P}_{\mathrm{itf}}\right)$ & $56.7(5.9)^{\mathrm{A}, \mathrm{b}}$ & $78.2(4.0)^{\mathrm{B}, \mathrm{b}}$ & $78.5(3.1)^{\mathrm{B}, \mathrm{b}}$ \\
Reduction ratio (\%) & $31.1(6.4)^{\mathrm{A}}$ & $11.7(3.7)^{\mathrm{B}}$ & $10.9(3.8)^{\mathrm{B}}$ \\
$\begin{array}{l}\text { Thickness from the adhesives-composite join } \\
\text { to the point of } 95 \% \text { DC of } \mathrm{P}_{\max }(\mu \mathrm{m})\left(\mathrm{D}_{95}\right)\end{array}$ & $5.9(2.0)^{\mathrm{A}}$ & $2.7(1.8)^{\mathrm{B}}$ & $7.0(2.0)^{\mathrm{A}}$ \\
\hline
\end{tabular}

Groups identified by the different superscript capital letters are significantly different in the same row $(p<0.05)$.

Groups identified by the different superscript small letters are significantly different between $\mathrm{P}_{\max }$ and $\mathrm{P}_{\text {itf }}$ of each material $(p<0.05)$.

as the tooth substrate. Light-cured adhesives leave behind an uncured resin layer (oxygen-inhibited layer) at the uppermost surface when polymerized in air ${ }^{1)}$. This uncured resin layer can polymerize while curing the overlying resin composite ${ }^{2}$. Additionally, adhesive resin monomers in the uncured layer could diffuse into the first layer of overlying resin composite and form an intermixed zone, in which fillers of resin composite have been sparsely dispersed ${ }^{17}$. In the intermixed zone, the uncured adhesive resin is thought to co-polymerize with hydrophobic monomers of resin composite ${ }^{18-20)}$. The co-polymerization behavior in this intermixed zone has been one of problems that requires further investigation and clarification. However, in this study with micro-Raman spectroscopy, this problem could not be dissolved because the Raman spectra of the intermixed zone prior to polymerization could not be acquired. Therefore, in this study, polymerization behavior was evaluated in the adhesive layer between the dentin surface and the intermixed zone with fillers of resin composite.

In this study, the one-step adhesives, TS and TSP, exhibited decreased DCs of the adhesive layer near the adhesive-composite join, and also the two-step self-etch adhesive SE showed decreased DC. A previous study evaluated the polymerization behavior of one-step selfetch adhesives on dentin in the absence of the oxygen inhibition effect by placing glass coverslips on the adhesives $^{14)}$. It was demonstrated that in the case of a strong $(\mathrm{pH}<1)$ self-etch adhesive, DC decreased as the distance from the dentin-adhesive interface increased, whereas for a mild ( $\mathrm{pH}>2)$ self-etch adhesive, DC was constant within the adhesive layer and higher than the strong self-etch adhesive ${ }^{14)}$. The $\mathrm{pH}$ of the adhesive has been shown to affect the polymerization behavior, depending upon the buffering effect of the demineralized dentin $^{14)}$. The one-step self-etch adhesive materials used in this study were classified as being in the mild category; for TS, $\mathrm{pH}$ is 2.7, and for TSP, $\mathrm{pH}$ is 2.3. These adhesive $\mathrm{pHs}$ would have less of an effect on the polymerization at the dentin surface. For SE, demineralization of the dentin is separately performed by the self-etching primer, and the adhesive agent contains acidic monomer, but not water. SE adhesive would not promote an acidic environment in the adhesive layer, which impairs the polymerization. Therefore, the reduction of DCs found in this study would not be due to impairment of polymerization in an acidic environment, and suggests that polymerization of the oxygen-inhibited layer at the top of adhesive layer could not reach maximum DC even after polymerization of the overlying resin composite. In the reduction area of $\mathrm{DCs}$, SE was thicker than TS and TSP. These thicknesses might not directly indicate thickness of the oxygen-inhibited layer, because solvent-diluted uncured monomers of one-step adhesives might easily infiltrate into the overlying resin composite and form a thicker intermixed zone, resulting in a lower reduction area of DC.

The polymerization behavior of light-cured resin composite is influenced by irradiated light intensity ${ }^{16)}$. The oxygen-inhibited layer of light-cured adhesive can be polymerized by light passing through the overlying resin composite ${ }^{18-20)}$. However, the light intensity is attenuated through the resin composite, depending upon the thickness and shade ${ }^{21,22)}$. Insufficient light intensity to oxygen-inhibited layer would be one of the reasons why the DCs of the adhesive layer near the adhesive-composite join decreased. Additionally, the residual water/solvent in adhesives is one of the factors affecting polymerization behavior ${ }^{5}$. TS contains water and organic solvent ${ }^{8)}$ and exhibited a significantly increased reduction ratio of DCs near the adhesivecomposite join and reduced maximum DC of the adhesive layer compared with SE, without water/solvent. The residual water/solvent impairs polymerization of the adhesive layer even when directly light-irradiated. In the oxygen-inhibited layer, the residual water/solvent may impair polymerization even more with insufficient light intensity irradiated indirectly through the resin composite.

TSP exhibited significantly higher maximum DC and a lower reduction ratio of DC at the adhesivecomposite join than TS. Both adhesives contain water and ethanol as solvents and also contain 2-hydroxyethyl methacrylate (HEMA). However, TSP utilizes a new cross-linkable hydrophilic monomer and a lower HEMA concentration. A low concentration of HEMA (up to 
$10 \%$ ) can improve the bonding efficacy of a one-step self-etch adhesive by enhancing the wetting behavior of the adhesive ${ }^{23)}$. However, a rise in the HEMA concentration lowers the vapor pressure of water, making it more difficult to remove the water from the adhesive ${ }^{24)}$, which would lead to impaired polymerization $^{25,26)}$. A lower HEMA concentration might have promoted an increase in DC in the adhesive layer of TSP. Additionally, the photo-initiation system could also affect polymerization behavior in the adhesive layer ${ }^{27-29)}$. Camphorquinone (CQ) has been widely used as a photo-initiator in adhesive agents, however it would be isolated within the hydrophobic phase or incompatible with hydrophilic HEMA because of its hydrophobic property ${ }^{30)}$, which would bring up the question as to whether $\mathrm{CQ}$ can sufficiently initiate polymerization of HEMA in the aqueous domain ${ }^{31}$. It was reported that water-soluble photo-initiator systems could increase DC of a model Bis-GMA/HEMA adhesive in the presence of water compared with $\mathrm{CQ}$ initiator system ${ }^{31}$. TS utilizes a CQ-initiation system, while TSP includes a new photo-initiator as well as CQ. Further research is required to improve the DC of onestep self-etch adhesive in the adhesion between dentincomposite.

Within the limitation of this study, it was concluded that in the adhesion between dentin-composite, DCs of one- and two-step self-etch adhesive decreased near the adhesive-composite join. This reduction of DC indicates that polymerization of the oxygen-inhibited layer at the top of the adhesive could not reach maximum DC even after polymerization of the overlying resin composite. Additionally, the reduction behavior of DC was dependent upon the materials, which may have been influenced by residual water/solvent, monomer components and/or the polymerization initiation system of the adhesives. One-step self-etch adhesives act as permeable membranes even after polymerization and permit water movement across their thickness, which could accelerate elution of uncured monomers ${ }^{32-35}$. The lowered DC from monomer to polymer cause the low chemical stability and high solubility of adhesives ${ }^{36-37}$. Therefore, the lowered DC near the adhesive-composite join might compromise long-term stability between onestep self-etch adhesive and composite. Indeed, previous long-term durability studies of resin-dentin bonds have demonstrated that one-step self-etch adhesive recorded increased failures between the adhesive-composite join after long-term water storage ${ }^{9)}$. In this study, resin composite of transparent shade was used as the overlying composite material. When universal or opaque shade composites were used, the reduction ratio of DCs near the adhesive-composite join might increase because the light intensity reaching the oxygeninhibited layer would be further attenuated than using the translucent shade composite. Polymerization of the oxygen-inhibited layer at the top of the adhesive layer is an important problem that should be considered when placing resin composite restoration using a onestep self-etch adhesive.

\section{REFERENCES}

1) Shawkat ES, Shortall AC, Addison O, Palin WM. Oxygen inhibition and incremental layer bond strengths of resin composites. Dent Mater 2009; 25: 1338-1346.

2) Kim JS, Choi YH, Cho BH, Son HH, Lee IB, Um CM, Kim CK. Effect of light-cure time of adhesive resin on the thickness of the oxygen-inhibited layer and the microtensile bond strength to dentin. J Biomed Mater Res B Appl Biomater 2006; 78: 115-123.

3) De Munck J, Van Landuyt K, Peumans M, Poitevin A, Lambrechts P, Braem M, Van MeerBeek B. A critical review of the durability of adhesion to tooth tissue: methods and results. J Dent Res 2005; 84: 118-132.

4) Van Landuyt KL, De Munck J, Snauwaert J, Coutinho E, Poitevin A, Yoshida Y, Inoue S, Peumans M, Suzuki K, Lambrechts P, Van MeerBeek B. Monomer-solvent phase separation in one-step self-etch adhesives. J Dent Res 2005; 84: $183-188$.

5) Ye Q, Wang Y, Williams K, Spencer P. Characterization of photopolymerization of dentin adhesives as a function of light source and irradiance. J Biomed Mater Res B Appl Biomater 2007; 80: 440-446.

6) Cadenaro M, Breschi L, Rueggeberg FA, Suchko M, Grodin E, Agee K, Di Lenarda R, Tay FR, Pashley DH. Effects of residual ethanol on the rate and degree of conversion of five experimental resins. Dent Mater 2009; 25: 621-628.

7) Itthagarun A, Tay FR, Pashley DH, Wefel JS, Garcia-Godoy F, Wei SH. Single-step, self-etch adhesives behave as permeable membranes after polymerization. Part III. Evidence from fluid conductance and artificial caries inhibition. Am J Dent 2004; 17: 394-400.

8) Itoh S, Nakajima M, Hosaka K, Okuma M, Takahashi M, Shinoda Y, Seki N, Ikeda M, Kishikawa R, Foxton RM, Tagami J. Dentin bond durability and water sorption/ solubility of one-step self-etch adhesives. Dent Mater J 2010; 29: 623-630.

9) Shinoda Y, Nakajima M, Hosaka K, Otsuki M, Foxton RM, Tagami J. Effect of smear layer characteristics on dentin bonding durability of HEMA-free and HEMA-containing onestep self-etch adhesives. Dent Mater J 2011; 30: 501-510.

10) Ikeda T, De Munck J, Shirai K, Hikita K, Inoue S, Sano H, Lambrechts P, Van MeerBeek B . Effect of air-drying and solvent evaporation on the strength of HEMA-rich versus HEMA-free one-step adhesives. Dent Mater 2008; 24: 13161323.

11) Van Landuyt KL, Mine A, De Munck J, Jaecques S, Peumans M, Lambrechts P, Van MeerBeek B. Are one-step adhesives easier to use and better performing? Multifactorial assessment of contemporary one-step self-etching adhesives. J Adhes Dent 2009; 11: 175-190.

12) Xie C, Han Y, Zhao XY, Wang ZY, He HM. Microtensile bond strength of one- and two-step self-etching adhesives on sclerotic dentin: the effects of thermocycling. Oper Dent 2010; 35: 547-555.

13) Gauthier MA, Stangel I, Ellis TH, Zhu XX. Oxygen inhibition in dental resins. J Dent Res 2005; 84: 725-729.

14) Zhang $Y$, Wang Y. Distinct photopolymerization efficacy on dentin of self-etch adhesives. J Dent Res 2012; 91: 795-799.

15) Zhang Y, Wang Y. Improved degree of conversion of model self-etching adhesives through their interaction with dentine. J Dent 2012; 40: 57-63.

16) Seki N, Nakajima M, Kishikawa R, Hosaka K, Foxton RM, Tagami J. The influence of light intensities irradiated directly and indirectly through resin composite to self-etch adhesives on dentin bonding. Dent Mater J 2011; 30: 315-322.

17) Tay FR, King NM, Suh BI, Pashley DH. Effect of delayed activation of light-cured resin composites on bonding of allin-one adhesives. J Adhes Dent 2001; 3: 207-225. 
18) Vankerckhoven H, Lambrechts $P$, van Beylen M, Davidson CL, Vanherle G. Unreacted methacrylate groups on the surfaces of composite resins. J Dent Res 1982; 61: 791-795.

19) Kao EC, Pryor HG, Johnston WM. Strength of composites repaired by laminating with dissimilar composites. J Prosthet Dent 1988; 60: 328-333.

20) Truffier-Boutry D, Place E, Devaux J, Leloup G. Interfacial layer characterization in dental composite. J Oral Rehabil 2003; 30: 74-77.

21) Rueggeberg FA, Caughman WF, Curtis JW Jr, Davis HC. Factors affecting cure at depths within light-activated resin composites. Am J Dent 1993; 6: 91-95.

22) Davidson-Kaban SS, Davidson CL, Feilzer AJ, de Gee AJ, Erdilek N. The effect of curing light variations on bulk curing and wall-to-wall quality of two types and various shades of resin composites. Dent Mater 1997; 13: 344-352.

23) Van Landuyt KL, Snauwaert J, Peumans M, De Munck J, Lambrechts P, Van Meerbeek B. The role of HEMA in onestep self-etch adhesives. Dent Mater 2008; 24: 1412-1419.

24) Pashley EL, Zhang Y, Lockwood PE, Rueggeberg FA, Pashley DH. Effects of HEMA on water evaporation from waterHEMA mixtures. Dent Mater 1998; 14: 6-10.

25) Jacobsen T, Soderholm KJ. Some effects of water on dentin bonding. Dent Mater 1995; 11: 132-136.

26) Wang Y, Spencer P. Continuing etching of an all-in-one adhesive in wet dentin tubules. J Dent Res 2005; 84: 350354.

27) Ogunyinka A, Palin WM, Shortall AC, Marquis PM. Photoinitiation chemistry affects light transmission and degree of conversion of curing experimental dental resin composites. Dent Mater 2007; 23: 807-813.

28) Schroeder WF, Vallo CI. Effect of different photoinitiator systems on conversion profiles of a model unfilled light-cured resin. Dent Mater 2007; 23: 1313-1321.
29) Park J, Ye Q, Topp EM, Misra A, Kieweg SL, Spencer P. Effect of photoinitiator system and water content on dynamic mechanical properties of a light-cured bisGMA/HEMA dental resin. J Biomed Mater Res A 2010; 93: 1245-1251.

30) Wang Y, Spencer P, Yao X, Ye Q. Effect of coinitiator and water on the photoreactivity and photopolymerization of HEMA/camphoquinone-based reactant mixtures. J Biomed Mater Res A 2006; 78: 721-728.

31) Ye Q, Park J, Topp E, Spencer P. Effect of photoinitiators on the in vitro performance of a dentin adhesive exposed to simulated oral environment. Dent Mater 2009; 25: 452-458.

32) Tay FR, Pashley DH, Suh BI, Carvalho RM, Itthagarun A. Single-step adhesives are permeable membranes. J Dent 2002; 30: 371-382.

33) Tay FR, Pashley DH, Peters MC. Adhesive permeability affects composite coupling to dentin treated with a self-etch adhesive. Oper Dent 2003; 28: 610-621.

34) Tay FR, Frankenberger R, Krejci I, Bouillaguet S, Pashley DH, Carvalho RM, Lai CN. Single-bottle adhesives behave as permeable membranes after polymerization. I. In vivo evidence. J Dent 2004; 32: 611-621.

35) Tay FR, Pashley DH, Suh B, Carvalho R, Miller M. Singlestep, self-etch adhesives behave as permeable membranes after polymerization. Part I. Bond strength and morphologic evidence. Am J Dent 2004; 17: 271-278.

36) Tanaka K, Taira M, Shintani H, Wasaka K, Yamaki M. Residual monomers (TEG-DMA and Bis-GMA) of a set visible-light-cured dental resin composite when immersed in water. J Oral Rehabil 1991; 18: 353-362.

37) Pearson GJ, Longman CM. Water sorption and solubility of resin-based materials following inadequate polymerization by a visible-light curing system. J Oral Rehabil 1989; 16: 5761. 